Research Article

\title{
Experimental Study on the Effect of Expansive Agent on the Durability of Concrete in Civil Air Defense Engineering
}

\author{
Junbo Zhang, ${ }^{1}$ Jigang Zhang $\mathbb{D}^{1,2}$ Weiwei Xiao, ${ }^{1}$ Qianying Wang, ${ }^{3}$ and Feng Shao ${ }^{4}$ \\ ${ }^{1}$ School of Civil Engineering, Qingdao University of Technology, Qingdao 266033, China \\ ${ }^{2}$ Qingdao University of Technology, \\ Cooperative Innovation Center of Engineering Construction and Safety in Shandong Blue Economic Zone, \\ Qingdao 266033, China \\ ${ }^{3}$ School of Architecture Engineering, Qingdao Agricultural University, Qingdao 266033, China \\ ${ }^{4}$ College of Architecture and Urban Planning, Qingdao University of Technology, Qingdao 266033, China
}

Correspondence should be addressed to Jigang Zhang; jigangzhang@126.com

Received 19 February 2021; Accepted 25 April 2021; Published 12 May 2021

Academic Editor: Peter Majewski

Copyright (c) 2021 Junbo Zhang et al. This is an open access article distributed under the Creative Commons Attribution License, which permits unrestricted use, distribution, and reproduction in any medium, provided the original work is properly cited.

In this study, the effect of $8 \%$ UEA the reason why the UEA content is $8 \%$ is as follows: the expansion agent content in the actual mix proportion of the project is $8 \%$, which is selected in this test to fit the reality better. expansion agent on the compressive strength, chloride ion penetration resistance, and carbonation resistance of civil air defense concrete were studied by simulating the rapid carbonation and chloride solution immersion of concrete structure in coastal civil air defense engineering environment. The results of this study show that the early compressive strength of concrete decreased by adding the UEA expansion agent and was also affected by the curing time. Moreover, the addition of UEA expansion agent decreased the content of free chloride ions and calcium carbonate in concrete and reduced the early compressive strength of concrete.

\section{Introduction}

In the construction of civil air defense projects in coastal cities, the reinforced concrete structures often face the steel corrosion caused by water leakage due to the high underground water pressure and groundwater infiltration. Therefore, the domestic civil air defense projects have strict requirements for the impermeability grade of concrete. Engineering leakage water generally comes from concrete structure cracks, mainly caused by the volume changes in concrete because of the temperature changes and chemical reactions. To reduce concrete cracks and improve the impermeability of engineering, various types of expansion agents have emerged with time.

The principle of the expander is to produce some expansion crystals by the hydration of expansion components to compensate for the volume shrinkage of concrete, and the expansion crystals will affect the internal structure of concrete.
Concrete expansion agent [1-3] can compensate the shrinkage of concrete and improve the compactness, impermeability, waterproof, and crack resistance of concrete. The studies on expansion agents mainly focused on the expansion rate, shrinkage compensation, and limiting conditions of expansion agents $[4,5]$. For example, Huang et al. [6] applied HCSA expansion agent and domestic traditional U-type expanding agent (UEA) to ultra-high performance concrete (UHPC) paste without fiber and compared their shrinkage reduction effects; Park et al. [7] studied the effect of CSA expansive agent and metolatp 860 shrinkage reducer on the shrinkage of UHPC doped with steel fiber; Zheng et al. [8] studied the effect of sirenps100 and $\mathrm{f17a}$ on the shrinkage properties of UHPC without fiber; Wang et al. [9] investigated the characteristics of strength and expansion as well as coordination between strength and expansion of superplasticized middle-strength and highstrength concrete. Deng et al. [10] studied the effect of expansion agent and shrinkage reducing agent on the 
autogenous shrinkage of UHPC. Chen et al. [11] studied improving crack-resistance property of cement-stabilized aggregate mixtures with expansion agent.

Zhao and Liu [12] studied the effect of additives and cement varieties on the expansion performance of HCSA expansion agents, and Tao [13] studied the effect of type of expansion agent, dosage, and curing conditions on the expansion rate. Besides, a few studies investigated the effect of expansion agents on concrete durability. Zhang et al. [14] studied the effect of microexpansive preservatives on the mechanical properties and durability of cement concrete.

In this study, the effect of UEA expansion agent on the compressive strength, free chloride ion content, and calcium carbonate content of civil air defense engineering concrete was studied by the actual concrete mix proportion.

\section{Experimental}

2.1. Preparation of Concrete. The cement selected in this test is Zhonglian P.O 42.5 ordinary Portland cement produced by Qingzhou Zhonglian cement company. The grade II fly ash is produced by Weifang Electric Power Plant. The S95 grade ore powder is produced by Qingdao Zhongkuang Hongyuan Industry and Trade Co., Ltd.; Qingdao river sand was used in the experiment after passing through a $5 \mathrm{~mm}$ sieve, with a fineness modulus of 2.6. The coarse aggregate is in the range 5-20 $\mathrm{mm}$ continuous graded crushed stone. The UEA expansion agent produced by Shanghai Sanjia Building Materials Technology Co., Ltd., was selected. Polycarboxylate superplasticizer was selected, and tap water was used for mixing.

Two concrete mix proportions are used in this test, as listed in Table 1.

2.2. Experimental Plan. To simulate the service environment of civil air defense engineering concrete in the real marine atmosphere environment, rapid carbonation and chloride solution immersion drying and wetting cycle (drying-wetting cycle) test were used in this experiment. The dryingwetting cycle system is shown in Table 2.

The nonstandard specimen with a cube size of $100 \mathrm{~mm} \times 100 \mathrm{~mm} \times 100 \mathrm{~mm}$ was used for measuring the concrete compressive strength test, and the compressive strength and load values of $100 \mathrm{~mm}$ cubes with the curing ages of 7, 28, and 56 days were measured. The final concrete cube compressive strength was obtained by multiplying the measured strength value by the conversion factor of 0.95 .

In the wetting-drying cycle test of rapid carbonization and chloride salt immersion, the prism test block with a size of $100 \mathrm{~mm} \times 100 \mathrm{~mm} \times 400 \mathrm{~mm}$ and the length-width ratio of 4 was used, meeting the requirements of Standard for Test Methods of Long-Term Performance and Durability of Ordinary Concrete (GB/T 50082-2009). The carbonization test was carried out in a fast carbonization chamber. The parameters of the carbonization chamber were set as follows: $\mathrm{CO}_{2}$ concentration, $20 \pm 3 \%$; relative humidity, $70 \pm 5 \%$; temperature, $20 \pm 2^{\circ} \mathrm{C}$.
The concrete test block was cured with formwork for $48 \mathrm{~h}$ and then put in a standard curing room for 28 days. After curing, the test block was taken out, and its two opposite rectangular sides were reserved, and the other sides were sealed with epoxy resin. The sealed concrete blocks were used in a ventilated place for $48 \mathrm{~h}$ and then soaked in a $3.5 \%$ (seawater concentration) chloride solution. After soaking for four days, the samples were taken out and kept in an oven for two days at a temperature of $50 \pm 2^{\circ} \mathrm{C}$. After drying, the samples were taken out. Then the samples were cooled to room temperature and kept in a carbonization oven for rapid carbonization. The carbonization process conforms to the corresponding cycle system degree. This series of steps serves as a cycle. Because one cycle test is momentary, the test data after six cycles was used in this study.

After the test block completed the specified cycle, the concrete mill was used to grind the test block from the surface of the solution. When the grinding range is within the first $10 \mathrm{~mm}$ and in the range of $10-20 \mathrm{~mm}$, sample every 1 and $2 \mathrm{~mm}$, respectively. When sampling, the ground powder was passed through a $0.63 \mathrm{~mm}$ sieve. The sieved powder was placed in an oven for $120 \mathrm{~min}$, and the oven temperature was set at $105{ }^{\circ} \mathrm{C} \pm 2{ }^{\circ} \mathrm{C}$. After drying, the samples were immediately placed in a drying oven.

\subsection{The Method of Experiments}

2.3.1. Compressive Strength. The compressive strength of concrete was measured using an electrohydraulic servo universal pressure testing machine in the Civil Engineering Materials Laboratory of Qingdao University of Technology, according to the Standard of Test Methods for Mechanical Properties of Ordinary Concrete (GB/T 50081-2002).

\subsubsection{Free Chloride Concentration and Calcium Carbonate} Content. The free chloride concentration was measured according to the Specification of Test Code for Concrete of Water Transport Engineering (JTJ270-98); the content of calcium carbonate was measured using a DRB-C1 precise concrete carbonation measuring instrument. The measuring principle was to convert the pressure of carbon dioxide gas generated by a chemical reaction between calcium carbonate and excess hydrochloric acid into the digital display using a pressure transmitter. The corresponding mass fraction of calcium carbonate in the concrete was obtained by the pressure value table.

\section{Results and Discussion}

3.1. Compressive Strength. To analyze the effect of UEA expansion agent on the compressive strength of concrete under standard curing conditions, the compressive strength tests of two types of concrete blocks under standard curing conditions of 7,28 , and 56 days were measured. The test results are listed in Table 3. 
TABle 1: Concrete mix proportion $\left(\mathrm{kg} / \mathrm{m}^{3}\right)$.

\begin{tabular}{lcccccccc}
\hline Concrete number & Cement & Fly ash & Mineral powder & Stone & Sand & Expansive agent & Water reducer & Water \\
\hline $\mathrm{P}$ & 240 & 67 & 33 & 991 & 811 & 30 & 7.4 & 162 \\
$\mathrm{M}$ & 270 & 67 & 33 & 991 & 811 & 0 & 7.4 & 162 \\
\hline
\end{tabular}

TABLE 2: Drying and wetting cycle system.

\begin{tabular}{|c|c|c|c|c|}
\hline Circular system number & & Experiment & & \\
\hline S1 & Soaked in $3.5 \% \mathrm{NaCl}$ for 4 days & Dry for 2 days & Carbonized for 3 days & Cycle 6 times \\
\hline S2 & Soaked in $3.5 \% \mathrm{NaCl}$ for 4 days & Dry for 2 days & Carbonized for 5 days & Cycle 6 times \\
\hline S3 & Soaked in $3.5 \% \mathrm{NaCl}$ for 4 days & Dry for 2 days & Carbonized for 0 days & Cycle 6 times \\
\hline
\end{tabular}

TABLE 3: Concrete cube compressive strength value.

\begin{tabular}{|c|c|c|c|c|c|}
\hline Age & Specimen $(\mathrm{MPa})$ & $\begin{array}{c}\text { Specimen size } \\
(\mathrm{mm} \times \mathrm{mm} \times \mathrm{mm})\end{array}$ & Peak load $(\mathrm{kN})$ & $\begin{array}{l}\text { Measured value of compressive } \\
\text { strength }(\mathrm{MPa})\end{array}$ & Average compressive strength \\
\hline \multirow{3}{*}{ M-7d } & C30-1 & $100 \times 100 \times 100$ & 247.75 & 23.5 & \multirow{3}{*}{24.6} \\
\hline & $\mathrm{C} 30-2$ & $100 \times 100 \times 100$ & 281.53 & 26.7 & \\
\hline & C30-3 & $100 \times 100 \times 100$ & 258.67 & 23.4 & \\
\hline \multirow{3}{*}{ P-7d } & C30-1 & $100 \times 100 \times 100$ & 228.42 & 21.7 & \multirow{3}{*}{21.1} \\
\hline & C30-2 & $100 \times 100 \times 100$ & 217.89 & 20.7 & \\
\hline & $\mathrm{C} 30-3$ & $100 \times 100 \times 100$ & 220.00 & 20.9 & \\
\hline \multirow{3}{*}{ M-28d } & C $30-4$ & $100 \times 100 \times 100$ & 414.75 & 39.4 & \multirow{3}{*}{40.1} \\
\hline & C30-5 & $100 \times 100 \times 100$ & 408.07 & 38.8 & \\
\hline & C30-6 & $100 \times 100 \times 100$ & 444.88 & 42.3 & \\
\hline \multirow{3}{*}{ P-28d } & $\mathrm{C} 30-4$ & $100 \times 100 \times 100$ & 417.89 & 39.7 & \multirow{3}{*}{38.6} \\
\hline & C30-5 & $100 \times 100 \times 100$ & 394.74 & 37.5 & \\
\hline & C30-6 & $100 \times 100 \times 100$ & 406.32 & 38.6 & \\
\hline \multirow{3}{*}{ M-56d } & C30-7 & $100 \times 100 \times 100$ & 454.85 & 43.2 & \multirow{3}{*}{45.3} \\
\hline & $\mathrm{C} 30-8$ & $100 \times 100 \times 100$ & 465.81 & 44.3 & \\
\hline & C30-9 & $100 \times 100 \times 100$ & 507.97 & 48.3 & \\
\hline \multirow{3}{*}{ P-56d } & C30-1 & $100 \times 100 \times 100$ & 467.37 & 44.4 & \multirow{3}{*}{44.6} \\
\hline & C30-2 & $100 \times 100 \times 100$ & 491.58 & 46.7 & \\
\hline & $\mathrm{C} 30-3$ & $100 \times 100 \times 100$ & 449.47 & 42.7 & \\
\hline
\end{tabular}

The change curve of concrete compressive strength as shown in Figure 1 was obtained from the data listed in Table 3.

Figure 1 shows that the addition of an expansion agent has an obvious effect on the compressive strength of concrete at 7 days, 28 days, and 56 days under the same standard curing time. The test data show that, under different curing ages, the compressive strength of concrete with the expansion agent is less than that of concrete without the expansion agent, but with increasing curing time, the strength gap gradually narrowed down. In the test of compressive strength with the curing time of 7,28 , and 56 days, the compressive strength of concrete with an expansion agent is $85.7 \%, 96.26 \%$ and $98.45 \%$ of that of the reference concrete, respectively. For C30 low-grade concrete, the compressive strength of concrete decreases with the addition of expansion agent but is greatly affected by the curing age. At the age of 7 and 28 days, the compressive strength decreases by
$14.23 \%$ and $3.7 \%$, respectively; at the age of 56 days, the compressive strength is almost the same as that of the reference concrete.

The reason for this phenomenon may be attributed to the fact that the UEA expansion agent is a sulphoaluminate type expansion agent. In the process of concrete formation, the calcium hydroxide of the cement hydration product will react with some components in the expansion agent to form calcium sulphoaluminate hydrate (ettringite). Ettringite is a type of needle-like crystal, which will gradually grow and extend with the progress of the reaction, destroying the small pores and making it larger. The concrete blocks used in this experiment are only cured with mold for two days after forming and then demolded and standard cured for two days under standard conditions. Therefore, the growth of ettringite is not limited, and the concrete structure will become bulkier and bulkier, which will eventually decrease the concrete pressure resistance. However, this expansion 


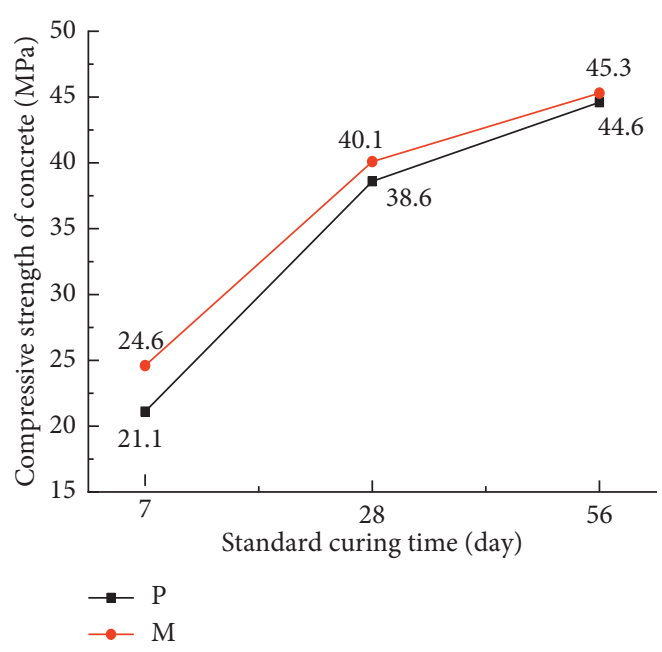

FIGURE 1: Curve of concrete compressive strength.

effect is more obvious in the early stage of strong growth, when the curing time is 28 days later. Therefore, the compressive strength after 56 days is the same as that of the reference concrete.

3.2. Free Chloride Concentration. This test does not consider the chloride ion in the concrete specimen due to external factors and test raw materials in the production process and takes the initial chloride ion content of the concrete specimen as 0 . Figure 2 shows the distribution of free chloride ion content in the concrete specimens under the cyclic system of this experimental design.

Due to the short cycle time of a single cycle, this study analyzed the effect of UEA expansion agent on the content of free chloride ions in the concrete by using the test data of test blocks after six cycles.

Figures 2(a), 2(b), and 2(c) show that, under the condition of the same cycle system and the same cycle period, the distribution of chloride ions in the carbonated concrete can be divided into three stages: convection zone, diffusion zone, and stable zone. There are two peaks in the convection zone. The analysis indicates that the formation of the first peak content is because of the initial precipitation of concrete under a dry environment. The chloride ion in the solution gradually infiltrates into the concrete under the action of capillary adsorption, so the convection direction of chloride ion is from the outside to the inside. However, the formation of the second peak content is more complex. The dried concrete sample was further soaked in the chloride solution for the designated period and further dried in the oven at $60^{\circ} \mathrm{C}$ for $48 \mathrm{~h}$. At this time, the concrete surface changes from the saturated state to the dry state. However, because of the presence of some liquid in the pores of the concrete, this part of pore liquid migrates outward due to the evaporation of the surface solution. The presence of postcondition will only affect the surface pore saturation of the concrete block and not the deeper pore saturation of concrete; therefore, the convection direction of chloride ions in the surface part is from the inside to the outside. In contrast, in the deeper part of the concrete, the chloride ions penetrating the surface of concrete diffuse to the interior of the concrete due to the concentration difference. Under both actions combined, the chloride ion content in the surface layer of concrete accumulates because of the convection effect, and the peak's value in the depth of the concrete also forms due to the diffusion effect. In contrast, there is a slight difference between the content of two peaks, because at this peak content, the concrete is in a saturated state, and the pore structure at different depths of the concrete is slightly different. However, there is a certain position between the two peaks of chloride ion content. At this position, some chloride ions diffuse from the inside to the outside and some from the outside to the inside, reducing the chloride ion content around this position and thus forming a low content. According to the analysis of Figures 2(a), 2(b), and 2(c), the depth of the convection zone in the concrete is approximately $6-11 \mathrm{~mm}$, which is slightly lower than the average reported depth of $10 \mathrm{~mm}$. The analysis indicates that the test period is too short and chloride ion penetration is limited; therefore, the depth of convection zone formed in this time is short.

The distribution curve of free chloride ion content in concrete with an expansion agent is similar to that in the control group, and the chloride ion distribution has three stages. However, the content of free chloride ion in the concrete mixed with the expansion agent is lower than that in the control group, probably because the curing of the concrete block for the drying-wetting cycle test was completed after 28 days. At this time, the effect of the expansion agent was saturated, and the crystalline expansion products filled the pores of the concrete, increasing the internal 


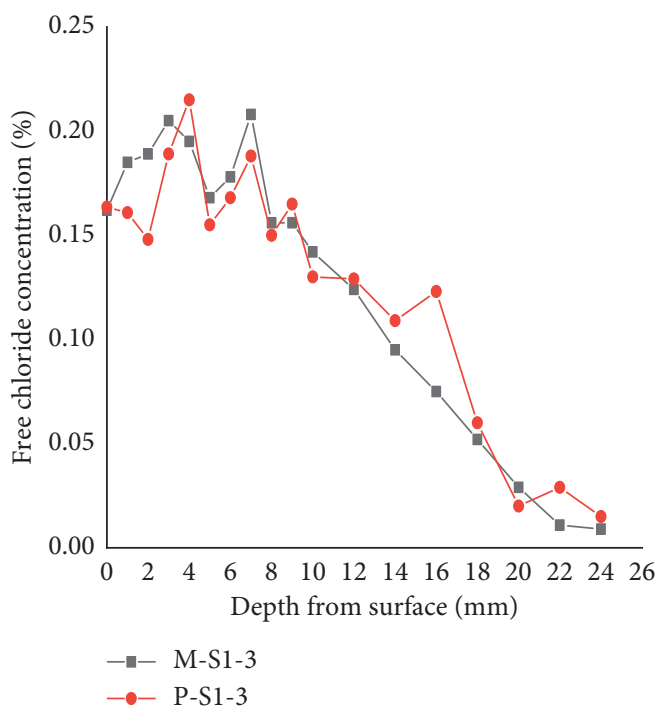

(a)

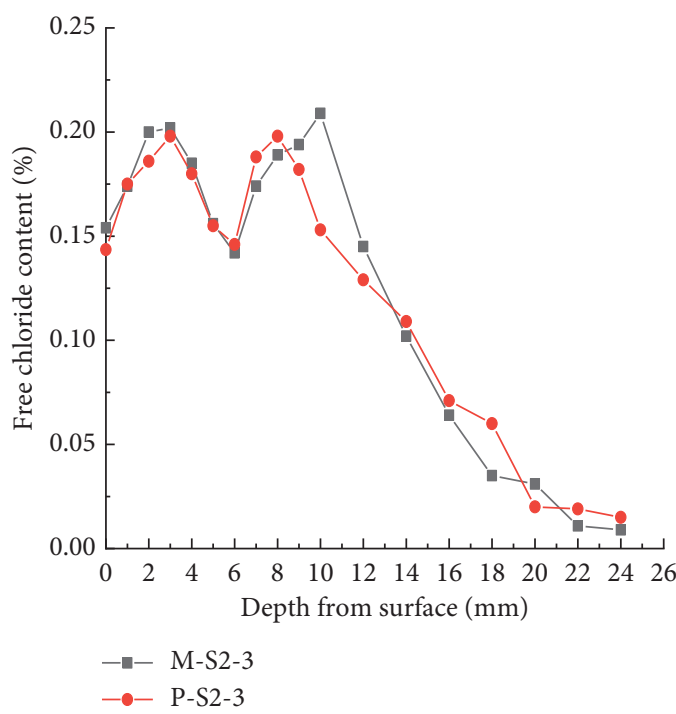

(b)

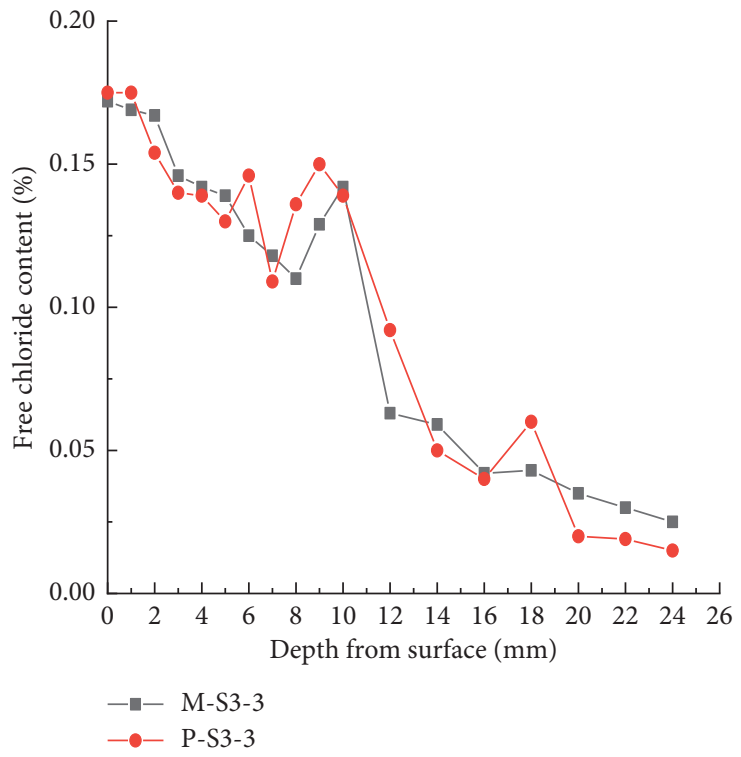

(c)

FIgURE 2: Distribution of free chloride ion content in concrete with different mix proportions and different systems. (a) Free chloride content diagram under S1 system. (b) Free chloride content diagram under S2 system. (c) Free chloride content diagram under S3 system.

compactness of the concrete and making it difficult for the chloride ions to recover from the inner penetration, which in turn decreases the free chloride ion content in the concrete and improves the anti-chloride ion penetration ability of concrete.

3.3. Calcium Carbonate Content of Concrete. The method of measuring the carbonation depth of concrete blocks by phenolphthalein reagent method is simple and easy to operate, but the measurement results are discrete and only roughly reflect the carbonation degree with poor accuracy. Therefore, according to the principle of carbon dioxide and calcium hydroxide reaction to form calcium carbonate precipitate, this test reflects the internal carbonation of concrete by measuring the content of calcium carbonate at each depth of concrete. The disadvantage of this method is that the ground powder samples of concrete test block must be taken and reacted with hydrochloric acid using specific instruments for measurement. This operation is more complex, but the accuracy is higher and thus this procedure truly reflects the carbonation degree of concrete. The distribution of calcium carbonate content in concrete with different cycle systems is shown in Figure 3.

In Figures 3(a) and 3(b) are the distributions of calcium carbonate content of two different mix proportion concrete under the S1 and S2 systems after six cycles, indicating that the distribution trend of calcium carbonate content in concrete mixed with the expansion agent under the same system is roughly the same as that in the ordinary 


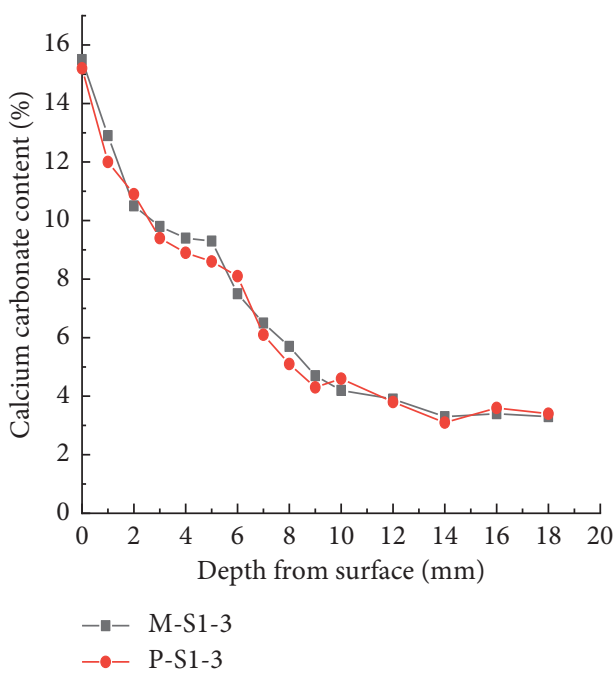

(a)

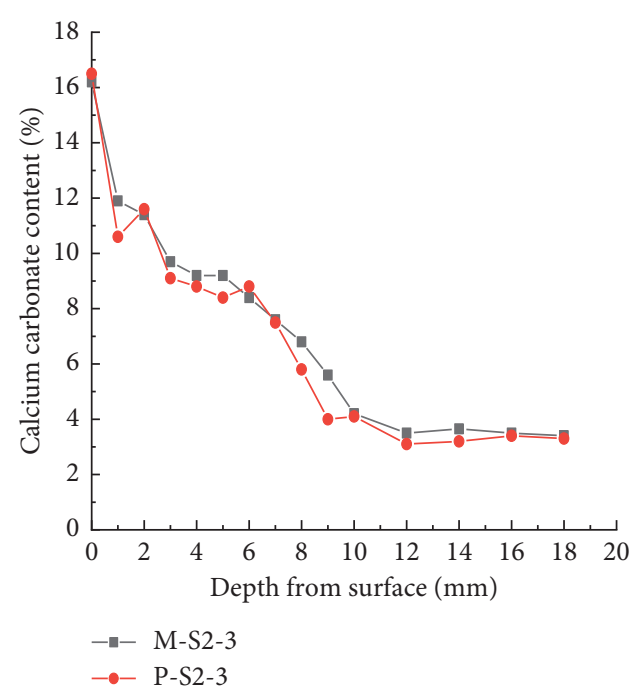

(b)

FIGURE 3: Distribution diagram of calcium carbonate content in different mix proportion. (a) Figure of calcium carbonate content in S1 system. (b) Figure of calcium carbonate content in S2 system.

concrete. There are four stages of concrete formation and drying: surface laitance zone, complete carbonation zone, partial carbonation zone, and noncarbonation zone. However, in the laitance zone, the calcium carbonate content of the concrete with an internal expansion agent is not different from that of the ordinary concrete, but the length of the complete carbonation zone of concrete with an internal expansion agent is less than that of the ordinary concrete. At the same depth of the partial carbonation zone, the calcium carbonate content of concrete with an internal expansion agent is lower than that of the ordinary concrete, and it enters a stable stage earlier. The reason may be that the carbonation of concrete is mainly affected by two aspects: the diffusion rate of carbon dioxide and the carbonate substances in the concrete. The diffusion rate of carbon dioxide is not only related to the external concentration, but also to the internal compactness of concrete. When the expansion agent is mixed in the concrete, the sulphoaluminate expansion agent will react with calcium hydroxide, the hydration product of early cement, to form ettringite (swelling source). This process consumes calcium hydroxide and reduces the carbonizable substances in the concrete, thus accelerating the carbonation of concrete. However, ettringite, which comates the expansion effect, will fill in the coarse pores in the concrete and will greatly improve the internal structure of the concrete and increase the density of concrete. With increasing density of concrete, the diffusion rate of carbon dioxide in the concrete decreases; therefore, the carbonation resistance of concrete depends on the leading factor. Zhao et al. [15] confirmed that, using the same amount of expansion agent as in this study, the expansion agent is the main factor leading to the change in the internal structure of concrete, thus improving the anticarbonation ability of concrete.

\section{Conclusion}

The effect of UEA expansion agent on the compressive strength, chloride ion penetration resistance, and carbonation resistance of civil air defense engineering concrete was studied by simulating the real service environment of civil air defense engineering in coastal cities by the method of rapid carbonation, chloride salt immersion drying, and wetting cycles. The experimental data of this study lead to the following conclusions:

(1) For low-grade concrete such as C30, under the condition of no mold limit, 8\% UEA expansion agent reduced the early compressive strength of concrete, and the compressive strength at 7-day curing age is $14.23 \%$ lower than that of the control group, but with increasing curing time, the reduction range is small and is the same as that of the reference concrete at 56 days.

(2) When the curing age reaches 28 days, the trend of free chloride ion content and calcium carbonate content in the concrete with an expansion agent is the same as that in the control group, but the internal content decreases.

(3) At $8 \%$ UAE content expansion agent, the concrete strength decreases, but it meets the strength grade requirements and effectively improves the chloride ion penetration resistance and carbonation resistance of the concrete structure. Therefore, the expansion agent with $8 \%$ UAE content has a wide application prospect for civil air defense engineering.

\section{Data Availability}

The data used to support the findings of this study have been deposited in the [figure] repository. Previously reported 
[PDF] data were used to support this study and are available at [reference file]. These prior studies (and datasets) are cited at relevant places within the text as references [2-5]. The data used to support the findings of this study are included within the article.

\section{Conflicts of Interest}

The authors declare that they have no conflicts of interest.

\section{References}

[1] C. Chen and D. Wang, "Experimental study on the shear performance of self-compacting concrete beam," Sichuan Building Science, vol. 46, no. 2, pp. 50-56, 2020.

[2] P. Yan, H. Lian, and Q. Xiao, "Several issues in the manufacture of shrinkage_compensating concrete us-ing expansive agent," Journal of the Chinese Ceramic Society, vol. 28, no. Supplement, pp. 42-45, 2000.

[3] J. Liu, Q. Tian, and M. Tang, "Influence of expansion agent and shrinkage reducing agent on shrinkage cracking of high performance concrete," Journal of Southeast University (NATURAL SCIENCE EDITION), vol. 36, no. Sup(II), pp. 195-199, 2006.

[4] Z. Wu, Zhang Hongzhi. Expansive Concrete, China Machine Press, Beijing, 2004.

[5] Li Fei and W. Qin, "Experimental study on the effect of HCSA expansive agent in high content fly ash concrete[J]," Expansive Agent and Expansive Concrete, vol. 19, no. 2, pp. 6-8, 2009.

[6] Z. Huang, Y. Liu, and C. Li, "Performance research of Ultra high performance concrete incorporating HCSA expansion agent," Materials Guide, vol. 29, no. 4, pp. 116-121, 2015.

[7] J.-J. Park, D.-Y. Yoo, S.-W. Kim, and Y.-S. Yoon, "Benefits of using expansive and shrinkage-reducing agents in UHPC for volume stability," Magazine of Concrete Research, vol. 66, no. 14, 2014.

[8] X. Zheng, N. Guocai, and H. Zhang, "Research on influence of shrinkage-reducing agentand expansive agent for shrinkage performance of UHPC," Concrete, vol. 9, no. 9, pp. 76-79, 2017.

[9] D. Wang, H. Chen, and S. Ouyang, "Investigation on mechanical property and expansion behavior of high strength superplasticized expansive concrete," Journal of The Chinese Ceramic Society, vol. 32, no. 4, pp. 454-459, 2004.

[10] Z. Deng, Y. Lian, and L. Zhao, "Influence of expansion agent and shrinkage reducing agent on autogenous shrinkage of UHPC," Journal of Beijing University of Technology, vol. 47, no. 1, pp. 61-69, 2021.

[11] D. Chen, "Study on crack-resistance property of cementstabilized aggregate mixtures with expansion agent," Heb Jiaotong ence and Technology, 2005.

[12] S. Zhao and Li Liu, "Study on Adaptability of HCSA expansive agent with chemical admixture and cement," in Proceedings of the 4th National Symposium on Concrete Expansive Agents, no. 2, pp. 1-5, China Silicate Society, Shenzhen, China, 2006.

[13] X. Tao, "Factors influencing the expansion rate of cement-based cementitious materials with expansion agent," Fujian Jianshe Science and Technology, vol. 5, no. 5, pp. 39-41+48, 2009.

[14] X. Zhang, Y. Liu, X. Li, W. Wu, and H. Yang, "Effect of microexpansion preservatives on the durability of cement concrete," New Building Materials, vol. 47, no. 12, pp. 15-18+34, 2020.

[15] S. Zhao and L. Liu, "Effect of expansive agent on carbonation of concrete with fly ash and its mechanism," in Proceedings of the 4th National Symposium on Concrete Expansive Agents, no. 2, pp. 17-22, Hangzhou, China, 2008. 